\title{
Discrimination learning as a function of internal stimuli
}

JAMES BOWEN AND DON STRICKERT ARLINGTON STATE COLLEGE
Twenty-four rats received irregular $50 \%$ partial reinforcement. Half the intertrial intervals were $15 \mathrm{sec}$. and half were $5 \mathrm{~min}$. For $12 \mathrm{Ss}$, consideration of both the goal event of the previous trial and length of the intertrial interval allowed reliable prediction of the goal event on the ensuing trial. The remaining $12 \mathrm{Ss}$ constituted a control group. The experimental Ss ran significantly faster on reinforced than nonreinforced trials at both short and long intertrial intervals, though discrimination was poor at the longer interval.

Capaldi (1964) explicates evidence that indicates discriminably different internal cues are present on trials following nonreinforcement than are present on trials following reinforcement. Research by Pavlov (1927) on delayed conditioning indicates that time also is a powerful internal stimulus.

The problem in the present study was whether rats could solve a complex discrimination involving an interaction between the above mentioned cues, i.e., time and cues generated by different reward conditions.

Method

The Ss were 24 naive Wistar strain albino rats which were about 90 days old at the beginning of training. The apparatus was a straight alley runway $72 \mathrm{in.} \mathrm{in}$ overall length, 5 in. wide, and enclosed by 6-in. high sides covered with hinged hardware cloth. A 2.5-in. high metal food cup was attached to the end of the alley. A 10-in. treadle at the beginning of the alley started a Standard Electric Timer when $\mathrm{S}$ was placed onto it. A photocell mounted $4 \mathrm{in}$. from the end of the goal section stopped the timer when the beam was broken. A guillotine type door placed 14 in. from the end of the alley prevented retracing. The entire apparatus was painted a flat gray.

The Ss were handled and adjusted to a $22.5 \mathrm{hr}$. deprivation schedule for eight days. The Ss were then randomly divided into two groups of 12 each, and experimental training began on Day 9. All Ss received irregular $50 \%$ partial reinforcement. Half the intertrial intervals (ITI) were $5 \mathrm{~min}$. and half were $15 \mathrm{sec}$. For Group $E$, the probability that reinforcement $(R)$ followed nonreinforcement $(\mathrm{N})$ was $\mathbf{. 5 2}$. The probability that $R$ followed $R$ was .48 . The probability of $R$ at the long ITI was .52 , and at the short ITI, .48. However, for six Ss in Group $E$, if any trial were $N$, the next trial was $R$ if the ITI were $15 \mathrm{sec}$, and $\mathrm{N}$ if the ITI were $5 \mathrm{~min}$. If any trial were $R$, the next trial was $N$ if the ITI were $15 \mathrm{sec}$, and $\mathrm{R}$ if $5 \mathrm{~min}$. For the other six Ss, these contingencies were reversed. Group $\mathrm{C}$ constituted a control group and the goal event could not be reliably predicted.
Each $S$ received eight trials per day; Group $E$ for 30 days, Group $\mathrm{C}$ for 15 days. On $\mathrm{R}$ trials, $\mathrm{S}$ ate wet mash for 20 sec.; on $\mathrm{N}$ trials, $\mathrm{S}$ was confined for $30 \mathrm{sec}$. Results

All analyses were done on mean log running times. By 120 trials, the Ss in Group $E$ were running faster on $\mathbf{R}$ than $\mathrm{N}$ trials at both ITIs. For Group $\mathrm{C}$, the difference between $\mathbf{R}$ and $\mathrm{N}$ trials over the last three days of acquisition was insignificant $(F=.36, d f=1 / 11)$, as was the interaction between reward condition and ITI $(F=1.5$, $\mathrm{df}=1 / 11$ ). The $\mathrm{Ss}$ in Group $\mathrm{C}$ did run faster at the long than the short ITI $(F=6.2, d f=1 / 11, p<.05)$. In Group $E$, discrimination was poor at the long ITI so training was continued to 240 trials to see if the discrimination would improve. It did not. Using the means of the last 24 of each kind of trial, $E$ inferred that Ss ran faster at the long ITI ( $F=90, \mathrm{df}=1 / 11, p<.001)$, and on $R$ trials $(F=99, \mathrm{df}=1 / 11, \mathrm{p}<.001)$. The interaction between reward condition and ITI was also significant $(F=107$, $\mathrm{df}=1 / 11, \mathrm{p}<.001$ ). Considering only those trials at the long ITI, Ss ran faster on $R$ trials $(F=8.22, d f=1 / 11$, $p<.05)$. Ss also ran faster on $R$ trials at the short ITI $(\mathrm{F}=131, \mathrm{df}=1 / 11, \mathrm{p}<.001)$.

\section{Discussion}

The results support one current trend in research, i.e., the attempt to account for a great deal of the systematic variance in behavior on the basis of internal cues. The principal difficulty with the present study is the greater discriminatory power Ss showed at the short ITI over the long ITI. One possible explanation is that the cue functioning after a particular reward condition loses its intensity with time and thereby becomes less salient. As the cue becomes embedded in the stimulus complex in which it occurs, the discrimination should become more difficult.

The function of time in the revised aftereffects model (Capaldi, 1964) has not been explicitly stated. The results of the present study suggest that time should be a variable in the model, both because time interacts with the aftereffect and because of the possibility of intensity changes in the aftereffect as a function of time.

\section{References}

Capaldi, E. J. Effect of N-length, number of different N-lengths, and number of reinforcements on resistance to extinction. $J$. exp. Psychol., 1964, 68, 230-239.

Pavlov, I. P. Conditioned reflexes. (Trans. G. V. Anrep), New York: Dover Publications, Inc., 1960.

\section{Note}

1. This investigation was supported in part by Public Health Service Research Grant MH 10041-01 from the National Institute of Mental Health. 